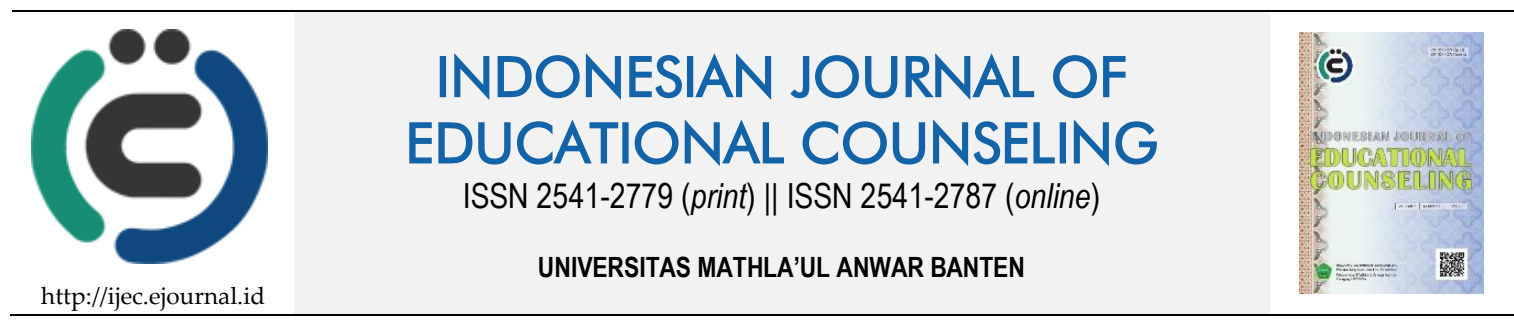

Research Based Article

\title{
Deskripsi Perilaku Kecemasan Komunikasi Mahasiswa Bimbingan dan Konseling Universitas Pendidikan Indonesia
}

\author{
Hasna Nurul Sani ${ }^{1}$, Euis Farida², Eka Sakti Yudha² \\ 1,2 Universitas Pendidikan Indonesia, Indonesia
}

\begin{tabular}{ll}
\hline Article History & ABSTRACT \\
\hline Received: 12.11.2020 & COMMUNICATION APPREHENSION TENDENCY ON STUDENTS \\
24.12.2020 & GUIDANCE AND COUNSELING AT INDONESIA UNIVERSITY OF \\
Accepted: 07.01.2021 & EDUCATION Adequate competence in communicating without experiencing \\
Available online: 29.01.2021 & communication apprehension is very needful for the student to be able to \\
& communicate effectively, and achieve success in academic or career in the \\
& future. Communication apprehension would affect negatively in life. This study \\
& aims to determine the description of communication apprehension tendency of \\
& student guidance and counseling at the Indonesia University of Education. \\
& Respondent in this study is student guidance and counseling 2nd grade at the \\
& Indonesia University of Education in aggregate 33 students. The data collection \\
& process is through instruments with the Personal Report of Communication \\
& Apprehension (PRCA-24). The approach used is quantitative with descriptive \\
& research methods. The results of the study describe the percentage of \\
& achievement scores of students' communication apprehension tendencies in the \\
& moderate category is amount to 23 students, 2) students guidance and \\
& counseling experience high communication apprehension in the interpersonal \\
& conversation context.
\end{tabular}

KEYWORDS: Communication Apprehension, PRCA-24, Student.

DOI: $10.30653 / 001.202151 .66$

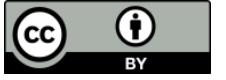

This is an open access article distributed under the terms of the Creative Commons Attribution 4.0 International License, which permits unrestricted use, distribution, and reproduction in any medium, provided the original work is properly cited. (c) 2021 Hasna Nurul Sani, Euis Farida, Eka Sakti Yudha.

\section{PENDAHULUAN}

Sebagai makhluk sosial, Manusia senantiasa terlibat dan berinteraksi dengan orang lain, baik secara kelompok maupun secara personal, dan dalam interaksinya tersebut manusia melakukan komunikasi (Rakhmat, 2011, p. 3). Proses komunikasi merupakan hal yang mendasar dalam berbagai situasi pada kehidupan manusia, baik secara pribadi, sosial, atau profesional (Ruben \& Stewart, 2013, p. 4). Melalui komunikasi, seseorang dapat merencanakan masa depan, membentuk kelompok. Selain itu komunikasi juga dibutuhkan agar manusia dapat menyampaikan informasi, opini, ide, konsepsi, pengetahuan, perasaan, sikap, perbuatan dan lain sebagainya kepada sesamanya (Widjaja, 2010, p. 4). Kompetensi yang baik dalam berkomunikasi merupakan salah satu

${ }^{1}$ Corresponding author's address: Program Studi Bimbingan dan Konseling, FIP Universitas Pendidikan Indonesia; Jl. Setiabudi Bandung, Indonesia. Email: hasnanuru1953@gmail.com 
kunci keberhasilan. Hal tersebut diperkuat dengan salah satu studi yang dilakukan secara ekstensif di kalangan pengusaha, bahwa kemampuan komunikasi lisan maupun komunikasi tulisan termasuk ke dalam empat belas keterampilan yang paling penting (Ruben \& Stewart, 2013, p. 5)

Karier di segala bidang memerlukan kemampuan seseorang untuk menganalisis situasi komunikasi, mengembangkan strategi komunikasi yang efektif, bekerjasama secara efektif dengan orang lain, dan menerima serta menyajikan gagasan secara efektif (Ruben \& Stewart, 2013, p. 5). Oleh karena itu, dapat disimpulkan bahwa kemampuan untuk dapat berkomunikasi secara efektif sangat dituntut pada siapapun, termasuk mahasiswa yang tengah melaksanakan studi untuk mencapai kesuksesan akademik pada masa perkuliahan maupun kariernya di masa depan.

Seorang Mahasiswa pada umumnya berada pada masa transisi dari masa remaja menuju dewasa yang terjadi pada usia 18-25 tahun (Arnett dalam Santrock, 2012, p. 6). Selanjutnya, Siswoyo (2007, p. 121) mendefinisikan mahasiswa sebagai individu yang tengah menuntut ilmu pada tingkat perguruan tinggi, baik negeri maupun swasta atau lembaga lain yang setaraf dengan perguruan tinggi.

Berdasarkan uraian tersebut dapat disimpulkan bahwa mahasiswa adalah seorang peserta didik yang berada pada rentang usia 18-25 tahun yang tengah menuntut ilmu di tingkat perguruan tinggi.

Pada tingkat Perguruan Tinggi, mahasiswa dihadapkan dengan situasi belajar yang menuntut mahasiswa untuk lebih aktif, mandiri, serta berkesadaran tinggi untuk mencari informasi yang diperlukan dalam perkuliahan. Hal tersebut diperlukan dalam menjalani berbagai aktivitas perkuliahan, antara lain mempresentasikan makalah di depan kelas, mengkonsultasikan skripsi dengan dosen pembimbing, menghadapi berbagai ujian praktik, saat diadakan diskusi kelompok (Santoso, 1998).

Menurut Ayres (2005), mahasiswa kerapkali mengalami kesulitan ketika berada dalam situasi komunikasi, baik dalam proses belajar di kelas maupun dalam suasana informal di luar kelas. Blackburn \& Davidson (2004, p. 54) menyebutkan bahwa salah satu penyebab terjadinya kesulitan komunikasi adalah adanya kecemasan komunikasi (dalam psikologi disebut communication apprehension) yang dialami mahasiswa.

Communication apprehension di definisikan sebagai ketakutan atau kecemasan terkait dengan komunikasi dengan orang lain maupun orang banyak (McCroskey \& Richmond, 1982, p. 458). Seseorang dengan tingkat communication apprehension yang tinggi cenderung selalu mencoba menarik diri dari pertemuan yang menuntut dirinya terlibat dengan situasi komunikasi baik dengan cara menghindari pertemuan sepenuhnya atau mengurangi partisipasinya apabila pertemuan tidak dapat dihindari (McCroskey \& Richmond, 1976, p. 14).

Communication apprehension dikonseptualisasikan sebagai penyebab yang mempengaruhi keberhasilan mahasiswa (McCroskey, dkk, 1989, p. 100). Sebagaimana dijelaskan oleh Carter dkk (2008, p. 3) bahwa communication apprehension mempengaruhi individu baik dari segi sosial, psikologis, karier dan akademis. Berdasarkan hal tersebut McCroskey \& Fionnan (McCroskey, dkk, 1989, p. 101) menyatakan bahwa mahasiswa yang mengalami communication apprehension akan berusaha menghindari situasi yang memerlukan bentuk komunikasi lisan dalam pengaturan akademik atau proses pembelajaran, seperti berdiskusi dengan teman atau berbicara di hadapan guru atau dosen. 
Penelitian terkait dengan kecemasan komunikasi communication apprehension) dilakukan oleh Adeyemi, Adekunle \& Muhammad (2017, p. 80) menunjukkan bahwa sebagian besar responden dari penelitian yang dilakukan terhadap mahasiswa di beberapa universitas di Nigeria rata-rata mengalami communication apprehension dan ini berimplikasi pada kemampuan kerja, yang meskipun tingkat communication apprehension mahasiswa di beberapa universitas di Nigeria tersebut terbilang tidak terlalu tinggi, namun masalah tersebut perlu untuk diatasi.

Kecemasan komunikasi (communication apprehension) yang dialami oleh mahasiswa apabila tidak ditangani dengan baik dapat membentuk pribadi yang pasif, sedangkan dalam proses perkuliahan di kelas mahasiswa dituntut untuk senantiasa berperan aktif, baik dalam proses diskusi, maupun ketika menyampaikan materi. Selain itu, khususnya bagi mahasiswa bimbingan dan konseling sebagai calon guru BK atau konselor sangat dituntut untuk memiliki kemampuan berkomunikasi yang efektif, baik itu secara publik, personal maupun diskusi dengan kelompok kecil. Sebagaimana dijelaskan oleh Ruben \& Stewart (2013, p. 5) bahwa seorang guru, konselor atau politisi selain memiliki kemampuan teknis diperlukan juga kemampuan komunikasi untuk dapat tampil secara kompeten.

Pasifnya mahasiswa dalam berkomunikasi apabila terus dibiarkan akan berpengaruh terhadap hasil prestasi akademik, dimana mahasiswa tidak dapat mengkomunikasikan ide, permasalahan ataupun memberikan respon terhadap proses perkuliahan yang berpengaruh terhadap perkembangan akademik serta pencapaian kesuksesan mahasiswa tersebut.

Berangkat dari kondisi tersebut, peneliti tertarik untuk melakukan penelitian untuk mengetahui gambaran tingkat perilaku kecemasan komunikasi (communication apprehension) pada mahasiswa bimbingan dan konseling. Melalui penelitian ini diharapkan dapat menjadi bahan pertimbangan untuk pihak universitas serta pembimbing akademik agar dapat merumuskan program yang dapat membantu mahasiswa dalam mengatasi kecemasan komunikasi (communication apprehension) yang dialami.

\section{METODE}

Metode penelitian ini menggunakan metode deskriptif, dengan tujuan untuk memperoleh gambaran dari fenomena-fenomena yang ada dan mendapatkan jawaban dari permasalahan yang tengah terjadi. Penelitian deskriptif (descriptive research) merupakan suatu metode penelitian yang ditujukan untuk menggambarkan fenomenafenomena yang ada, yang berlangsung pada saat ini atau saat yang lampau (Sukmadinata, 2005, p. 54). Penelitian ini bertujuan untuk memperoleh gambaran dari perilaku communication apprehension yang dimiliki oleh Bimbingan dan Konseling Universitas Pendidikan Indonesia, Kota Bandung, Jawa Barat.

Populasi penelitian yaitu seluruh mahasiswa aktif Bimbingan dan Konseling angkatan 2017. Sampel penelitian ditentukan dengan teknik random sampling. Sampel penelitian adalah sebagian mahasiswa Bimbingan dan Konseling semester 3 yang berjumlah 33 mahasiswa. Instrumen yang digunakan untuk mengumpulkan data penelitian adalah The Personal Report of Communication Apprehension (PRCA) yang dibuat oleh McCroskey (1984). Terdiri dari 24 item dalam PRCA yang didalamnya menilai individu dalam berkomunikasi di depan umum, yang meliputi enam item pertanyaan 
dalam empat setting berkomunikasi, yaitu: berbicara dalam diskusi kelompok (group discussion), berbicara dalam suatu pertemuan (meetings), dengan individu lain (interpersonal conversations), dan berbicara di depan umum (public speaking) berbicara.

Teknik analisis data yang digunakan adalah analisis deskriptif yang bertujuan untuk menganalisis data secara umum dengan teknik statistik.

\section{HASIL DAN PEMBAHASAN}

Berdasarkan hasil analisis data kecenderungan kecemasan komunikasi (communikation apprehension) yang dilakukan, mahasiswa yang memiliki kecemasan komunikasi yang tinggi sebanyak 5 orang $(15 \%)$, kecemasan komunikasi sedang sebanyak 23 orang $(69,7 \%)$ dan 5 orang mahasiswa lainnya memiliki kecemasan komunikasi pada level rendah. Maka, secara umum dapat disimpulkan bahwa kecenderungan kecemasan komunikasi mahasiswa Bimbingan dan Konseling Universitas Pendidikan Indonesia semester 3 tahun akademik 2018/2019 berada pada kategori sedang. Profil umum kecemasan komunikasi mahasiswa Bimbingan dan Konseling Universitas Pendidikan Indonesia semester 3 tahun akademik 2018/2019 secara rinci dapat dilihat dari tabel berikut.

Tabel 1. Profil Kecemasan Komunikasi (Communication Apprehension) Mahasiswa Bimbingan dan Konseling Semester 3 Tahun Ajaran 2018/2019

\begin{tabular}{lllll}
\hline No & Skor & Kategori & Frekuensi & $\%$ \\
\hline 1 & $>69$ & Tinggi & 5 & 15 \\
\hline 2 & $51-69$ & Sedang & 23 & 69,7 \\
\hline 3 & $<51$ & Rendah & 5 & 15
\end{tabular}

Berdasarkan Tabel 1, dapat diketahui bahwa secara-rata-rata mahasiswa program studi bimbingan dan konseling Universitas Pendidikan Indonesia memiliki kecenderungan kecemasan dalam berkomunikasi yang sedang, yaitu 69,7\%. Kondisi ini menggambarkan bahwa pada umumnya mahasiswa Bimbingan dan Konseling Universitas Pendidikan Indonesia semster 3 mampu berkomukasi dalam berbagai situasi namun tidak dipungkiri bahwa mereka juga dapat mengalami kecemasan dalam suatu situasi yang menggangu mereka. Sebagaimana dijelaskan oleh (McCroskey \& Richmond ( 1984, hlm 346) dalam penelitiannya bahwa orang-orang dengan tingkat kecemasan komunikasi sedang mengetahui bahwa suatu situasi mengganggu mereka ketika berkomunikasi namun tidak dengan situasi lainnya. Selanjutnya orang yang memiliki skor kecemasan komunikasi yang tinggi cenderung mengalami kecemasan dalam hampir berbagai situasi sedangkan individu dengan skor kecemasan komunikasi yang rendah cenderung sangat sedikit mengalami kecemasan ketika berkomunikasi.

Hasil penelitian juga menggambarkan tingkat kecemasan komunikasi yang dialami mahasiswa berdasar pada empat konteks komunikasi. Rincian hasil dapat dilihat dari Tabel 2. 
Tabel 2. Profil Kecemasan Komunikasi (Communication Apprehension) Berdasarkan Konteks Komunikasi

\begin{tabular}{|c|c|c|c|c|}
\hline \multirow[t]{2}{*}{ No } & \multirow[t]{2}{*}{ Situasi Komunikasi } & \multicolumn{3}{|c|}{ Tingkat Kecemasan Komunikasi (Orang/Persentase) } \\
\hline & & Tinggi & Sedang & Rendah \\
\hline 1 & Group Discussion & 2 orang / $6 \%$ & 27 orang/ $81,8 \%$ & 4 orang / $12 \%$ \\
\hline 2 & Meetings & 2 orang / $6 \%$ & 29 orang/ $88 \%$ & 2 orang / $6 \%$ \\
\hline 3 & $\begin{array}{l}\text { Interpersonal } \\
\text { Conversations } \\
\text { (Dyadic) } \\
\end{array}$ & 8orang $/ 24 \%$ & 22 orang/ $66,6 \%$ & 3 orang / $9 \%$ \\
\hline 4 & Public Speaking & 3 orang / $9 \%$ & 26 orang / $79 \%$ & 4 orang / $12 \%$ \\
\hline
\end{tabular}

Dilihat dari Tabel 2, dapat dilihat hasil perhitungan sub-skor dari kecemasan komunikasi berdasarkan konteks komunikasi, yang terdiri dari konteks diskusi kelompok (group discussion), pertemuan (meetings), percakapan interpersonal (interpersonal conversation), dan berbicara di depan publik (public speaking). Hasil yang didapat menunjukkan bahwa sebanyak $6 \%$ mahasiswa mengalami kecemasan komunikasi yang tinggi dalam konteks diskusi kelompok kecil dan dalam situasi rapat/pertemuan, 24\% mengalami kecemasan tinggi dalam konteks percakapan interpersonal dan sebanyak $9 \%$ mengalami kecemasan tinggi dalam situasi berbicara di depan publik. Oleh karena itu dapat disimpulkan bahwa dari hasil penelitian tersebut, mahasiswa Bimbingan dan Konseling Universitas Pendidikan Indonesia semster 3 tahun ajaran 2018/2019 cenderung mengalami kecemasan komunikasi dalam situasi percakapan interpersonal atau dapat disebut dengan kecemasan komunikasi antar pribadi.

Ada beberapa faktor yang dapat menyebabkan kecemasan komunikasi interpersonal menurut McCroskey (Devito, 1997), diantaranya 1) apabila individu kurang memiliki pengalaman dan keterampilan dalam berkomunikasi, 2) Situasi komunikasi yang berada dalam pengawasan atau penilaian, seperti ketika wawancara atau melakukan konsultasi skripsi dengan dosen, 3) situasi komunikasi yang berhubungan dengan orang lain yang memiliki status sosial atau jabatan yang lebih tinggi dan 4) Pengalaman masa lalu akan mempengaruhi seseorang dalam memberikan respon.

Hal ini berbeda dengan hasil penelitian yang dilakukan oleh McCroskey (1984) yang menunjukkan bahwa mahasiswa cenderung mengalami kecemasan yang tinggi dalam konteks berbicara di depan publik.

\section{SIMPULAN}

Secara umum kecenderungan kecemasan komunikasi mahasiswa Bimbingan dan Konseling Universitas Pendidikan Indonesia semester 3 tahun akademik 2018/2019 berada pada kategori sedang. Sebanyak $24 \%$ orang mahasiswa mengalami kecemasan tinggi dalam konteks percakapan interpersonal yang mungkin dapat disebabkan oleh kurangnya rasa percaya diri atau kurangnya kemampuan berhubungan serta berkomunikasi yang efektif dengan orang lain.

Maka, untuk dapat mereduksi kecemasan komunikasi yang dialami mahasiswa ini hendaknya pihak universitas serta dosen pembimbing mempertimbangkan untuk membantu mahasiswa dalam mengatasi permasalahan kecemasan komunikasi yang dialaminya, baik dengan membuat program atau meningkatkan peranan dosen 
pembimbing akademik bukan hanya untuk membantu mahasiswa dalam permasalahan akademik melainkan membantu permasalahan mahasiswa dari segi pribadi dan sosialnya.

\section{REFERENSI}

Ayres, J. (1986). Perceptions of speaking ability: An explanation for stage fright. Communication Education, 35(3), 275-287.

Blackburn, IM, \& Davidson, K. (2004). Terapi kognitif untuk depresi dan kecemasan. Semarang: IKIP Press.

Punyanunt-Carter, N. M., Wrench, J. S., Corrigan, M. W., \& McCroskey, J. C. (2008). An examination of reliability and validity of the religious communication apprehension scale. Journal of Intercultural Communication Research, 37(1), 1-15.

Devito, J. A. (1997). Komunikasi antar manusia. Diterjemahkan oleh: Ir. Agus Maulana. Jakarta: Profesional Book.

McCroskey, J. C., \& Richmond, V. P. (1976). The effects of communication apprehension on the perception of peers. Western Journal of Communication (includes Communication Reports), 40(1), 14-21.

McCroskey, J. C., \& Richmond, V. P. (1982). Communication apprehension and shyness: Conceptual and operational distinctions. Communication Studies, 33(3), 458-468.

McCroskey, J. C., Booth-Butterfield, S., \& Payne, S. K. (1989). The impact of communication apprehension on college student retention and success. Communication Quarterly, 37(2), 100-107.

McCroskey, J. C., \& Richmond, V. P. (1984). Communication apprehension and small group communication. In R. S. Cathcart, \& L.A Samovar (Eds), Small Group Communication, Fourth Ed. (pp. 342-356).

Rakhmat, J. (2011). Psikologi komunikasi. Bandung: Remaja Rosda Karya.

Ruben, B. D., \& Stewart, L.P. (2013). Communication and human behavior. Edisi kelima. Diterjemahkan oleh Ibnu Hamad. Jakarta: Rajawali Pers.

Santoso, H. P., Rahardjo, T., Sulistyani, H. D., \& Luktuantoro, T. (1998). Tingkat kecemasan komunikasi mahasiswa dalam lingkup akademis. Semarang: Universitas Diponegoro Semarang

Santrock, J.W. (2012). Life-span development: Perkembangan masa-hidup. Edisi ketigabelas. Jakarta: Erlangga

Siswoyo, D. (2007). Ilmu pendidikan. Yogyakarta: UNY Press

Sukmadinata, N. S. (2007). Metode penelitian pendidikan. Bandung: Remaja Rosda Karya

Widjaja, H. A. W. (2010). Komunikasi: Komunikasi dan hubungan masyarakat. Edisi 1, Cetakan Keenam. Jakarta: Bumi Aksara. 